\title{
INFLAMMATORY CELL INFILTRATION AND HIGH ANTIBODY PRODUCTION IN BALB/c MICE CAUSED BY NATURAL EXPOSURE TO LUTZOMYIA LONGIPALPIS BITES
}

\author{
FRANCINALDO SILVA, REGIS GOMES, DEBORACI PRATES, JOSÉ C. MIRANDA, BRUNO ANDRADE, \\ MANOEL BARRAL-NETTO, AND ALDINA BARRAL \\ Centro de Pesquisas Gonçalo Moniz, FIOCRUZ, Salvador, Bahia, Brazil; Faculdade de Medicina, Universidade Federal da Bahia, \\ Salvador, Bahia, Brazil
}

\begin{abstract}
Sand flies inject saliva into the mammalian host when probing for a blood meal. Understanding the initial vertebrate reactions against sand fly saliva is important for possible interventions because these insects transmit diseases to humans and other animals. Little is known of these reactions to New World sand flies. Repeated exposure of BALB/c mice to Lutzomyia longipalpis bites leads to local inflammatory cell infiltration comprised of neutrophils, macrophages, and eosinophils. Total IgG and IgG1 antibodies react predominantly with three major protein bands (45, 44, and 16 kD) of the insect saliva by Western blot. The injection of immune serum previously incubated with salivary gland homogenate induced an early infiltration with neutrophils and macrophages, suggesting the participation of immune complexes in triggering inflammation.
\end{abstract}

\section{INTRODUCTION}

Leishmaniasis is transmitted by sand flies and affects millions of people worldwide, particularly in developing countries. In the New World, Lutzomyia longipalpis is the principal vector of Leishmania chagasi, the agent of American visceral leishmaniasis. The female sand fly injects saliva into the mammalian host when it probes for a blood meal. ${ }^{1}$ This saliva contains a number of substances that are able to interfere with host hemostatic, inflammatory, and immune responses. These substances may actually benefit vector-delivered Leishmania parasites. ${ }^{2,3}$ Leishmania major co-inoculated with $L u$. longipalpis salivary gland homogenate $(\mathrm{SGH})$ induces more severe disease than parasites without saliva. ${ }^{4-6}$ Mice exposed to uninfected Phlebotomus papatasi bites developed antibodies against saliva, as well as a strong delayed-type hypersensitivity (DTH) response. This cellular response is mainly a $\mathrm{T}$ cell CD4+-dependent immune response. There is infiltration of inflammatory cells at the site of the bite 24-48 hours after challenge with SGH that may help the sand fly to feed faster compared with a normal skin site. ${ }^{7}$ In mice (BALB/c and $\mathrm{C} 57 \mathrm{BL} / 6$ ), a prior exposure to $P$. papatasi bites led to a reduction in the severity of the dermal lesions at the site of L. major injection, suggesting that the DTH response against saliva provides a protective effect. ${ }^{8-10}$ Much less information is available on the role of Lu. longipalpis bites in leading to hypersensitivity and humoral responses in animal models. In the present study, we explored the humoral and cellular immune responses against $L u$. Longipalpis saliva after natural bites, as well as the role of immune complex in promoting early inflammation.

\section{MATERIALS AND METHODS}

Mice. Female BALB/c mice (4-6 weeks old) were obtained from the Centro de Pesquisas Gonçalo Moniz (CPqGM)/ FIOCRUZ animal facility. The experimental procedures were reviewed and approved by the Animal Care and Utilization Committee of the CPqGM/FIOCRUZ.

Sand flies and preparation of salivary glands. Lutzomyia longipalpis (Cavunge strain) were reared at the Laboratório de Imunoparasitologia/CPqGM (Salvador, Bahia, Brazil) us- ing a mixture of rabbit feces and rabbit rations as larval food. Sand fly colonies were maintained at $26^{\circ} \mathrm{C}$. Adult male sand flies were offered cotton containing a sucrose solution, and females were fed on slightly anesthetized hamsters. Salivary glands from $\mathrm{Lu}$. longipalpis females were prepared from 5-7day-old laboratory bred flies. Salivary glands were dissected, placed in phosphate-buffered saline (PBS) on ice, and stored at $-70^{\circ} \mathrm{C}$. Immediately before use, the glands were sonicated and microfuged at $12,000 \times g$ for two minutes. These supernatants were used for experiments.

Sensitization of mice. Groups of mice $(n=12)$ were sensitized five times by natural exposure to 15 uninfected female Lu. longipalpis in the left ear at 10-day intervals. Ten days after the last exposure to sand fly bites, animals received 10 $\mu \mathrm{L}$ of SGH (0.2 pairs) or saline injected intradermally with a Hamilton (Reno, NV) syringe and a 29-gauge needle. Ears from unexposed mice and from those exposed five times to Lu. longipalpis bites were removed 2 and 48 hours after the challenge.

Anti-sand fly saliva serologic testing. Anti-saliva antibodies were evaluated by an enzyme-linked immunosorbent assay (ELISA) using a protocol previously described. ${ }^{8}$ Briefly, ELISA plates were coated overnight at $4^{\circ} \mathrm{C}$ with $\mathrm{SGH}(5 \mu \mathrm{g} / \mathrm{mL})$ as antigen. The plated were then washed with PBS- $0.05 \%$ Tween and blocked with PBS- $0.05 \%$ Tween plus $5 \%$ bovine serum albumin. Sera from control and immunized mice (1:10 dilution) were added and the plates were incubated overnight at $4{ }^{\circ} \mathrm{C}$. The plates were then washed and incubated with alkaline phosphate-conjugated anti-mouse IgG antibody (Sigma, St. Louis, MO), followed by alkaline phosphate substrate ( $p$-nitrophenylphosphate; Sigma) and read at $405 \mathrm{~nm}$. For detection of serum-specific IgG1, IgG2a, and IgG2b, serum samples were used at 1:50 dilutions and detected with alkaline phosphate-conjugated rat anti-mouse IgG1, IgG2a, and $\mathrm{IgG} 2 \mathrm{~b}$ (Jackson ImmunoResearch Laboratories, West Grove, PA) monoclonal antibodies (1:1,000 dilutions).

Western blots. Western blots of salivary gland antigens were performed as described elsewhere. ${ }^{8}$ Western blot analysis was performed by electrophoresis of SGH (80 salivary gland pairs) on a $16 \%$ Tris-glycine gel containing a single long well (Invitrogen, Carlsbad, CA). After transfer to nitrocellulose membranes, the membranes were blocked with $5 \%$ non- 
fat milk in PBS- $0.05 \%$ Tween overnight at $4{ }^{\circ} \mathrm{C}$. The membranes were placed on a mini-protean II multiscreen apparatus (Bio-Rad Laboratories, Hercules, CA) and incubated with serum (1:10 dilution) in blocking buffer for one hour at room temperature. This was followed by an incubation in anti-mouse IgG alkaline phosphatase-conjugated antibody (1:1,000 dilution) for one hour. Bands were visualized using alkaline phosphatase substrate (Promega, Madison, WI) and the reaction was stopped by washing the membrane with deionized water.

Intradermal injection of SGH pre-incubated with immune serum. A group of naive mice $(n=6)$ was intradermally injected in the ear with $10 \mu \mathrm{L}$ of serum from mice immunized against $\mathrm{Lu}$. longipalpis saliva previously (incubated for one hour at $37^{\circ} \mathrm{C}$ with 0.2 pairs of SGH.). Ears were removed at 2 and 48 hours after inoculation for histologic evaluation.

Histologic processing. Ears were fixed in $10 \%$ phosphatebuffered formalin and embedded in paraffin. Sections $(5 \mu \mathrm{m})$ were stained with hematoxylin and eosin. Cellular counting was performed by light microscopy. Results are presented as number of cells in SGH-injected ears minus the number of the same cell population observed in saline-injected contralateral ears.

Statistical analyses. Student's paired $t$-test was used to compare the groups using GraphPad (San Diego, CA) Prism Software.

\section{RESULTS}

Exposure of BALB/c mice to $L u$. longipalpis biting five times led to significant production of $\mathrm{IgG}$ antibody to saliva (Figure 1). Under the conditions evaluated, most of the IgG production was represented by the IgG1 subclass, whereas IgG2a and $\mathrm{IgG} 2 \mathrm{~b}$ remained near background levels observed in unexposed animals (Figure 1). Analysis by Western blot of sera from mice exposed to Lu. longipalpis biting showed that three major bands were recognized. A $45-\mathrm{kD}$ salivary protein was recognized by five of six serum samples tested. Two other

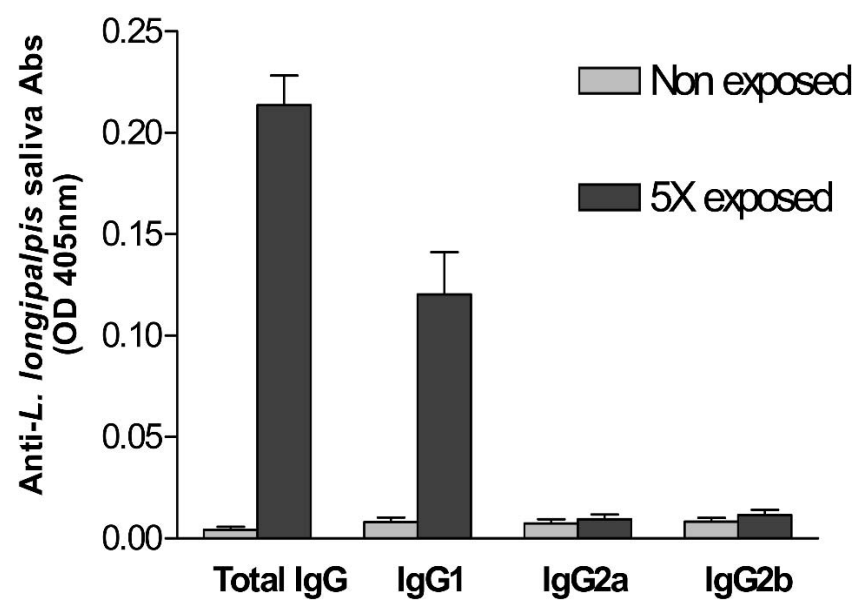

Figure 1. Anti-Lutzomyia longipalpis saliva IgG, IgG1, IgG2a, or IgG2b antibody levels in sera from BALB/c mice determined by an enzyme-linked immunosorbent assay. Mice were exposed five times to L. longipalpis bites (10-day intervals) or not exposed. Sera were collected 10 days after the last exposure. Error bars represent the mean and SD of the optical density (OD) at $405 \mathrm{~nm}$. The Student's paired $t$-test was used to compare the groups. Abs $=$ antibodies.

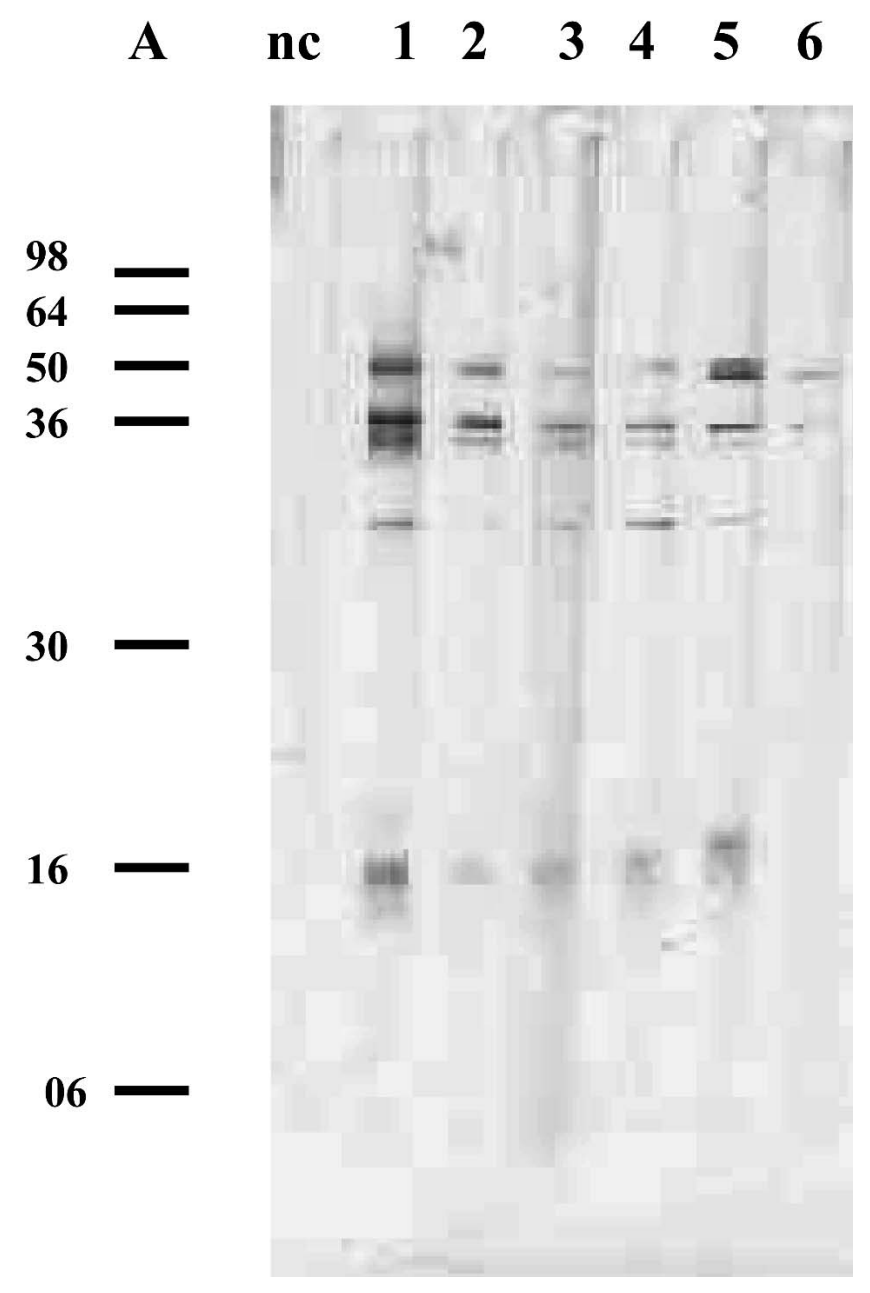

FIGURE 2. Western blot of Lutzomyia longipalpis salivary proteins recognized by sera from BALB/c mice. Sera were collected 10 days after the last exposure of mice exposed five times to sand flies bites (lanes 1-6). Values on the left are in kilodaltons. Lane $\mathrm{A}=$ molecular mass markers; lane $\mathrm{nc}=$ sera from negative controls.

proteins ( $44 \mathrm{kD}$ and $16 \mathrm{kD})$ were each recognized by three of the six serum samples (Figure 2).

Salivary gland homogenate $(0.2$ pairs in $10 \mu \mathrm{L})$ injected intradermally in the ears of non-exposed BALB/c mice led to a very modest infiltration of inflammatory cells both at 2 hours (Figure 3A) and 48 hours (Figure 3C) after challenge. Similar injections in mice exposed to sand fly bites five times led to an intense and diffuse inflammatory cell infiltration observed 2 hours (Figure 3B) after challenge and persisting up to 48 hours (Figure 3D).

To investigate the role of immune complexes in the observed inflammation, we injected immune sera previously incubated with SGH into the ears of naive mice. Two hours after injection, an inflammatory infiltrate composed of neutrophils and macrophages was observed by histologic examination (Figure 3E).

To better analyze such an inflammatory infiltration, we counted the number of cells present in the sections (Figure 4). Since the challenge of these animals was performed by needle injection of SGH, it was necessary to control for cell infiltration resulting from needle volume alone. Contralateral ears received saline under the same conditions, which led to mod- 

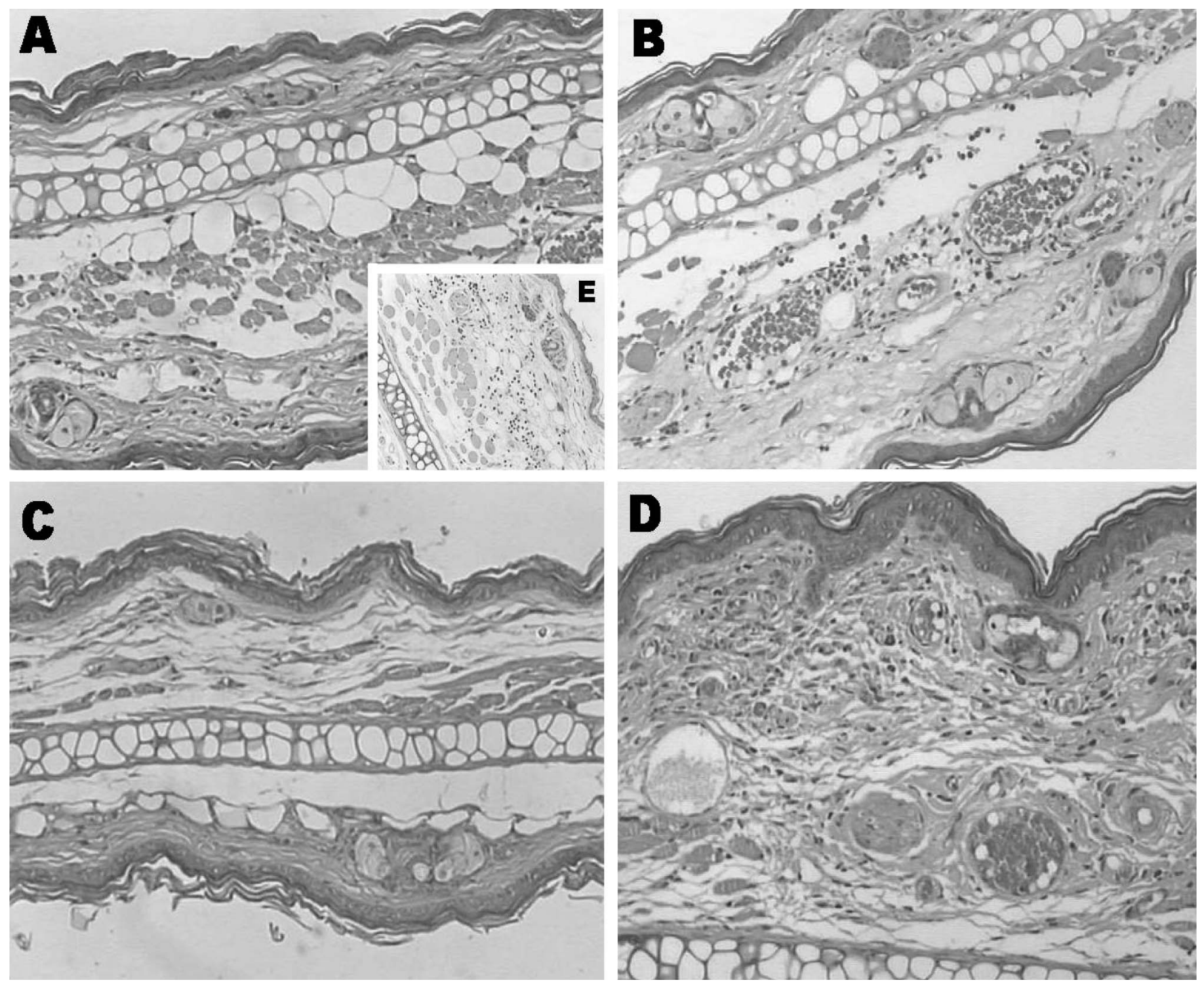

Figure 3. Histology of ears from BALB/c mice that were not exposed ( $\mathbf{A}$ and $\mathbf{C}$ ) or exposed five times (B and $\mathbf{D})$ to Lutzomyia longipalpis bites at 2 hours (A and $\mathbf{B})$ or 48 hours $(\mathbf{C}$ and $\mathbf{D})$ after challenge with intradermally injected salivary gland homogenate (SGH), (10 $\mu \mathrm{L}, 0.2$ pairs). A modest inflammatory cell infiltrate is observed 2 hours after SGH injection in unexposed mice (A), which subsides after 48 hours $(\mathbf{C})$. Sensitized animals exhibited a moderate and diffuse cellular infiltration 2 hours after challenge (B) that increases at 48 hours (D). Injection of SGH previously incubated with immune serum into the ears of unexposed BALB/c mice resulted in moderate and diffuse cell infiltration 2 hours after injection $(\mathbf{E})$. (Hematoxylin and eosin stained, original magnification $\times 40$.)

est cell infiltration. In each case, the number of cells present in the ear that received saline was subtracted from the number obtained in the SGH-injected ear of the same animal. Injection of SGH in unexposed animals induced cell recruitment similar to the injection of saline. Conversely, SGH injected into animals exposed five times to sand fly bites led to a potent recruitment of neutrophils, followed by macrophages and eosinophils two hours after challenge (Figure 4A). A reduction in neutrophils with increased recruitment of macrophages was the result in exposed animals 48 hours after SGH injection. (Figure 4B)

\section{DISCUSSION}

BALB/c mice exposed to repeated Lu. longipalpis bites developed local inflammation and antibodies to saliva when challenged with SGH. Significant IgG and IgG1, but not $\mathrm{IgG} 2 \mathrm{a}$ or IgG2b, anti-saliva antibody responses were elicited. Such a predominance of IgG1 antibodies with irrelevant IgG2a production suggests a preferential Th2 expansion. Sensitization to $P$. papatasi saliva has been reported to upregulate Th2 responses with interleukin-4 (IL-4) and IL-5 production in the epidermis. ${ }^{8}$ A predominant Th 2 response has also been reported against Aedes aegypti despite the presence of a delayed-type response in the skin. ${ }^{11}$ Individuals exposed to insect bites first develop a DTH response against insect saliva, which evolves into a predominant immediate type hypersensitivity response, followed later by desensitization. ${ }^{12}$ In an area endemic for visceral leishmaniasis, children showed antibodies to $L u$. longipalpis saliva with a mixed composition of IgG1 and IgE, suggesting a mixed Th1/Th2 response. ${ }^{13}$ We have recently reported that in human mono- 

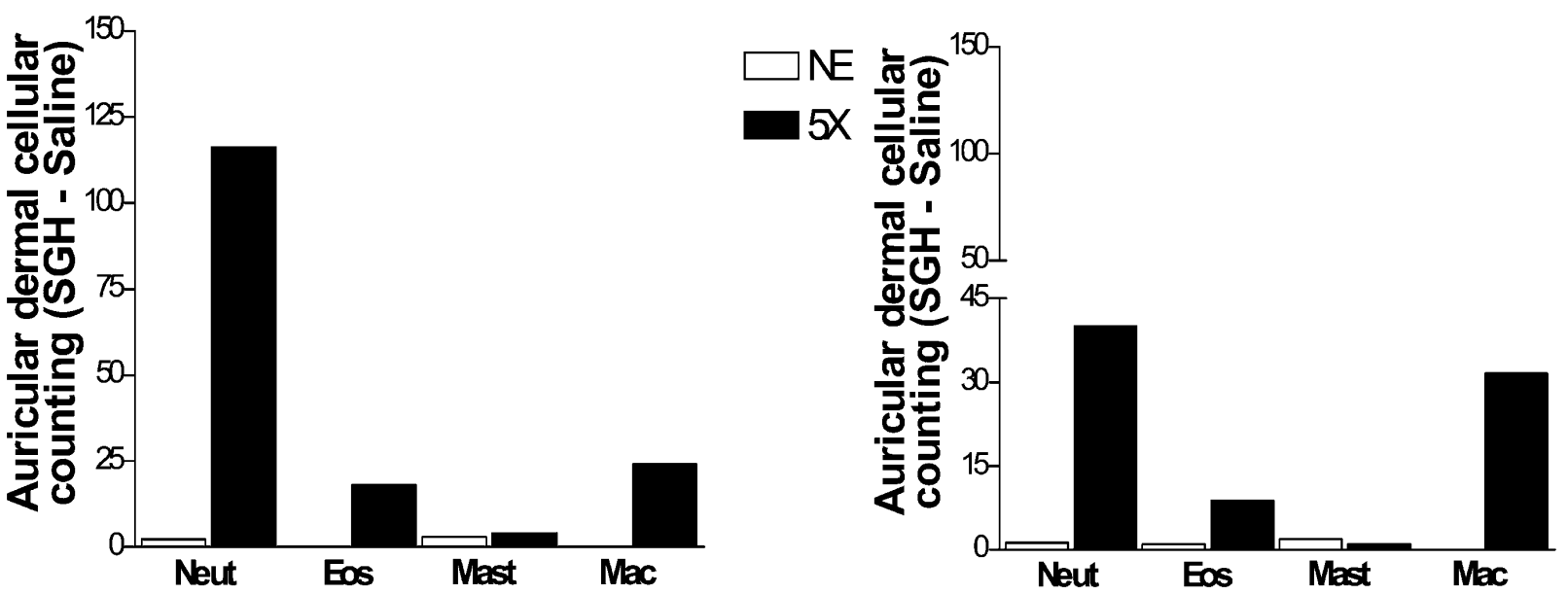

FIGURE 4. Cell numbers in the inflammatory infiltrate of the ear dermis of BALB/c mice that were not exposed (open bars) (NE) or exposed five times $(5 \mathrm{X})$ to sand fly bites (dark bars) at 2 hours $(2 \mathrm{~h})(\mathbf{A})$ or 48 hours $(48 \mathrm{~h})(\mathbf{B})$ after an intradermal challenge with syringe-injected salivary gland homogenate $(\mathrm{SGH})$. To control for needle trauma, the contralateral ear of each animal was injected with saline. Bars represent mean of 10 animals (SD of the original values was less than $10 \%$ of the mean). Neut $=$ neutrophils; Eos $=$ eosinophils; Mast $=$ mast cells; Mac $=$ macrophages.

cytes, SGH of Lu. longipalpis induced an increase in IL-6, IL-8, and IL-12p40 production, but a decrease in tumor necrosis factor $\alpha$ and IL-10 production. ${ }^{14}$ SGH affected the expression of co-stimulatory molecules (CD80 and CD86) on the surface of human monocytes and macrophages, but had little effect on dendritic cells. Taken together, these data suggest that SGH affects the innate and acquired immune responses, as well as inflammation, as shown in the present study.

Sera from immune mice recognized with a high frequency and a strong reaction the $45-\mathrm{kD}$ and $44-\mathrm{kD}$ proteins from Lu. longipalpis saliva. These proteins were also the major targets of human antibody response in an endemic area. ${ }^{12,15}$ Since these proteins are widely recognized, they are natural candidates for use as markers of exposure to Lu. longipalpis bites. If these strongly immunogenic proteins have further roles in impairing immune responses or facilitating parasite establishment, this remains to be demonstrated. The $15-\mathrm{kD}$ protein was also recognized by sera from mice exposed to $L u$. longipalpis bites. Immunization with the $15-\mathrm{kD}$ component from $P$. papatasi saliva was able to protect mice challenged with $L$. major plus SGH, inducing a strong inflammatory response. ${ }^{10}$

In this report, we have demonstrated that Lu. longipalpis saliva induces an intense and diffuse inflammatory infiltrate characterized by neutrophils, eosinophils, and macrophages in pre-exposed mice. This response was observed at 2 hours and sustained up to 48 hours after SGH challenge, whereas histologic analysis of the ear dermis showed no inflammatory reaction in control unexposed mice. It has been shown that prior exposure to $P$. papatasi saliva by bites of uninfected flies modifies the course of the L. major lesion. ${ }^{9}$ Such protection was associated with a strong cellular response and with interferon- $\gamma$ production at the site of parasite delivery. At the site of the reaction, pre-exposed mice exhibited an infiltration of neutrophils, eosinophils, macrophages, dendritic cells, and lymphocytes. When used for immunization, the $15-\mathrm{kD}$ protein from $P$. papatasi saliva induced a strong inflammatory reaction characterized by elevated numbers of neutrophils and eosinophils. ${ }^{10}$ Our results also showed a mixed infiltration with neutrophils, eosinophils, and macrophages. There was a modest presence of mast cells in the ear dermis of preexposed mice at both 2 and 48 hours after SGH challenge. This response is not a typical DTH reaction as induced by bacterial antigens such as the tuberculin reaction, which is predominantly a mononuclear cell infiltrate. We investigated the potential role of immune complexes in the observed cell infiltration. Two hours after injection of immune sera preincubated with $\mathrm{SGH}$ in the ear dermis of unexposed mice, there was an inflammatory infiltrate comprised of neutrophils and macrophages. Antigen-antibody complexes are produced during normal immune responses. Complement and Fc receptors activated by circulating immune complexes promote recruitment and activation of inflammatory cells, predominantly neutrophils and mast cells. In our work, there was a modest recruitment of mast cells.

In summary, our results suggest a predominant Th2 response developed in sensitized mice with IgG1 antibody production and with a putative role for immune complexes in cell recruitment. These results expand on the role of sand fly saliva in promoting an initial inflammatory response that may contribute to creating an inhospitable environment for the establishment of the parasite in the mammalian host.

Received May 17, 2004. Accepted for publication September 8, 2004.

Acknowledgments: We thank Edivaldo Passos for technical assistance with the insect colony and Robert Thompson (National Institutes of Health, Bethesda, MD) for helpful discussions.

Financial support: This work was supported by Tropical Medicine Research Center grant A130639 from the National Institutes of 
Health. Francinaldo Silva was supported by Coordenação de Aperfeiçoamento de Pessoal de Nível Superior (CAPES) (Brazil). Regis Gomes is the recipient of a Conselho Nacional de Desenvolvimento Científico e Tecnológico (CNPq) fellowship. Aldina Barral and Manoel Barral-Netto are Senior Investigators of the CNPq.

Authors' addresses: Francinaldo Silva, Regis Gomes, Deboraci Prates, José C. Miranda, Bruno Andrade, Manoel Barral-Netto, and Aldina Barral, Centro de Pesquisas Gonçalo Moniz, FIOCRUZ, R. Waldemar Falcão, 121, Brotas, 40.295-001, Salvador, Bahia, Brazil.

Reprint requests: Aldina Barral, Centro de Pesquisas Gonçalo Moniz, FIOCRUZ, R. Waldemar Falcão, 121, Brotas, 40.295-001, Salvador, Bahia, Brazil, Telephone: 55-71-356-4320 extension 215, Fax: 55-71-356-2255, E-mail: abarral@cpqgm.fiocruz.br.

\section{REFERENCES}

1. Titus RG, Ribeiro JMC, 1990. The role of vector saliva in transmission of arthropod-borne disease. Parasitol Today 6: 157159.

2. Ribeiro JMC, Rossignol PA, Spielman A, 1986. Blood-finding strategy of a capillary-feeding sand fly, Lutzomyia longipalpis. Comp Biochem Physiol 4: 683-686.

3. Charlab R, Valenzuela JG, Rowton ED, Ribeiro JM, 1999. Toward an understanding of the biochemical and pharmacological complexity of the saliva of a hematophagous sand fly Lutzomyia longipalpis. Proc Natl Acad Sci USA 96: 1515515160.

4. Titus RG, Ribeiro JMC, 1988. Salivary gland from the sand fly Lutzomyia longipalpis enhance Leishmania infectivity. Science 239: $1306-1308$.

5. Samuelson J, Lerner E, Tesh R, Titus R, 1991. A mouse model of Leishmania braziliensis braziliensis infection produced by coinjection with sand fly saliva. J Exp Med 173: 49-54.

6. Theodos CM, Ribeiro JM, Titus RG, 1991. Analysis of enhancing effect of sand fly saliva on Leishmania infection in mice. Infect Immun 59: 1592-1598.
7. Belkaid Y, Valenzuela JG, Kamhawi S, Rownton E, Sacks D, Ribeiro JMC, 2000. Delayed-type hypersensitivity to Phlebotomus papatasi sand fly bite: an adaptive response induced by the fly? Proc Natl Acad Sci USA 97: 6704-6709.

8. Belkaid Y, Kamhawi S, Modi G, Valenzuela JG, Noben-Trauth N, Rownton E, Ribeiro JMC, Sacks D, 1998. Development of a natural model of cutaneous leishmaniasis: powerful effects of vector saliva and saliva preexposure on the long-term outcome of Leishmania major infection in the mouse ear dermis. $J$ Exp Med 188: 1941-1953.

9. Kamhawi S, Belkaid Y, Modi G, Rowton E, Sacks D, 2000. Protection against cutaneous leishmaniasis resulting from bites of uninfected sand flies. Science 290: 1351-1354.

10. Valenzuela JG, Belkaid Y, Garfield MK, Mendez S, Kamhawi S, Rownton E, Sacks D, Ribeiro JMC, 2001. Toward a defined anti-Leishmania vaccine targeting vector antigens: characterization of a protective salivary protein. J Exp Med 194: 331342.

11. Chen YL, Simons FER, Peng Z, 1998. A mouse model of mosquito allergy for study of antigen-specific $\mathrm{IgE}$ and $\mathrm{IgG}$ subclass response, lymphocyte proliferation, and IL-4 and IFN- $\gamma$ production. Int Arch Allergy Immunol 116: 269-277.

12. Mellanby K, 1946. Natural history of vertebrate host response to insect bites. Nature 158: 554-558.

13. Gomes RB, Brodskyn C, de Oliveira CI, Costa J, Miranda JM, Caldas A, Valenzuela JG, Barral-Netto M, Barral A, 2002. Seroconversion against Lutzomyia longipalpis saliva concurrent with the development of anti-Leishmania chagasi delayedtype hypersensitivity. J Infect Dis 186: 1530-1534.

14. Costa DJ, Favali C, Clarêncio J, Afonso L, Conceição V, Miranda JC, Titus RG, Valenzuela J, Barral-Netto M, Barral A, Brodskyn CI, 2004. Lutzomyia longipalpis salivary gland homogenate impairs cytokine production and costimulatory molecule expression on human monocytes and dendritic cells. Infect Immun 72: 1298-1305.

15. Barral A, Honda E, Caldas A, Costa J, Vinhas V, Rowton ED, Valenzuela J, Charlab R, Barral-Netto M, Ribeiro JMC, 2000. Human immune response to sand fly salivary gland antigens: a useful epidemiological marker? Am J Trop Med Hyg 62: $740-745$. 